\title{
GC/MS Profiling and Ex Vivo Antibacterial Activity of Salvadora persica (Siwak) against Enterococcus faecalis as Intracanal Medicament
}

\author{
Nahla Ayoub ${ }^{1 D},{ }^{1}$ Nadia Badr, ${ }^{2}$ Saeed S Al-Ghamdi, ${ }^{1}$ Arwa Alzahrani, ${ }^{3}$ Rahaf Alsulaimani, ${ }^{3}$ \\ Afnan Nassar $\left(\mathbb{D},{ }^{4}\right.$ Rawabi Qadi, ${ }^{1}$ Ibtesam K. Afifi, ${ }^{5,6}$ and Noha Swilam $\left(\mathbb{D}{ }^{7}\right.$ \\ ${ }^{1}$ Department of Pharmacology and Toxicology, Faculty of Medicine, Umm Al-Qura University (UQU), Makkah, Saudi Arabia \\ ${ }^{2}$ Department of Dental Biomaterials, Faculty of Dentistry, Umm Al-Qura University (UQU), Makkah, Saudi Arabia \\ ${ }^{3}$ Bachelor of Dental Surgery, Faculty of Dentistry, Umm Al-Qura University (UQU), Makkah, Saudi Arabia \\ ${ }^{4}$ Department of Preventive Dentistry, Public Health, Faculty of Dentistry, Umm Al-Qura University (UQU), \\ Makkah, Saudi Arabia \\ ${ }^{5}$ Department of Basic and Clinical Oral Sciences, Faculty of Dentistry, Umm Al-Qura University (UQU), Makkah, Saudi Arabia \\ ${ }^{6}$ Department of Medical Microbiology and Immunology, Faculty of Medicine, Tanta University, Tanta, Egypt \\ ${ }^{7}$ Department of Pharmacognosy, Faculty of Pharmacy, The British University in Egypt (BUE), Cario, Egypt
}

Correspondence should be addressed to Nahla Ayoub; naayoub@uqu.edu.sa

Received 15 October 2021; Revised 3 December 2021; Accepted 9 December 2021; Published 27 December 2021

Academic Editor: Lidia Audrey Rocha Valadas

Copyright (C) 2021 Nahla Ayoub et al. This is an open access article distributed under the Creative Commons Attribution License, which permits unrestricted use, distribution, and reproduction in any medium, provided the original work is properly cited.

Introduction. Salvadora persica L. (S. persica, Siwak) has been used for many centuries as oral hygiene tools, particularly in Saudi Arabia. This study aimed to assess the effectiveness of $S$. persica petroleum ether extract (SPE) as an intracanal bactericidal for endodontic treatment against Enterococcus faecalis. Calcium hydroxide $\mathrm{Ca}(\mathrm{OH})_{2}$ gold standard intracanal medicament was used for comparison. Methods. The gas chromatography mass spectrometry (GC/MS) analysis was carried out to identify the components of SPE. First, the consistency of SPE was accomplished according to ANSI/ADA specification no 57. Forty-five single-rooted mandibular premolars were infected with that of E. faecalis suspension. Colony-forming units (CFU) were counted before the medicaments' application (CFU-1) and after seven days of their applications (CFU-2). Group I: SPE, Group II: positive control $\mathrm{Ca}(\mathrm{OH})_{2}$, and Group III: saline solution negative control. The microdilution method was applied to determine minimal inhibitory concentration (MIC) and minimal bactericidal concentration (MBC) of SPE. Results. Thirty-two compounds were identified (89.09\%), with main components of benzyl isothiocyanate (BITC) (33.32\%) and steroids (34\%). CFU before and after using SPE and $\mathrm{Ca}(\mathrm{OH})_{2}$ recorded a statistically significant reduction in bacterial count $(P=0.006)$ and $(P=0.01)$, respectively. There was an insignificant difference between CFU after using SPE and $\mathrm{Ca}(\mathrm{OH})_{2}(P=0.210)$. On the contrary, comparing both medicaments with the negative control saline group resulted in significant differences, $(P=0.001)$ and $(P=0.007)$, respectively. Moreover, the equality of minimum bactericidal concentration (MBC) and minimum inhibitory concentration (MIC) of SPE is recorded. Conclusion. This finding could be referred to the high content of bactericidal BITC in synergism with other antimicrobial components, representing $70.71 \%$ of SPE. Thus, SPE is a good candidate as an intracanal medicament, which warrants further investigation.

\section{Introduction}

The ultimate goal of an infected root canal preparation, including cleaning, shaping, and using the disinfectant solution, is to entirely remove bacteria, their by-product, and pulpal remnants. The microorganisms in the root canal of the teeth are principally responsible for pulpal/periapical diseases. The primary intraradicular infections have been caused by many members of endodontic bacterial communities [1]. Some of them are persistent pathological bacteria, including Streptococcus sanguinis, Streptococcus mutans, Enterococcus faecalis, Fusobacterium nucleatum, 
Porphyromonas gingivalis, and Prevotella intermedia [2]. However, E. faecalis is significantly more associated with asymptomatic cases of primary endodontic infections. Furthermore, E. faecalis is much more likely to be found in cases of failed endodontic therapy [3]. The antibacterial intracanal medication is used to eradicate bacteria in adults and children's root canal systems. Accordingly, the pain and inflammation of pulpal and periapical tissues are reduced $[4,5]$. This represents an optimal root canal disinfection protocol that guarantees a high success rate of root canal treatment [6-8]. The most commonly used intracanal medicament is $\mathrm{Ca}(\mathrm{OH})_{2}$ because of its significant bactericidal effect and inhibition of inflammatory exudates [8].

The foremost commonly utilized irrigants in endodontics are sodium hypochlorite $(\mathrm{NaOCl})$, ethylenediamine-tetra-acetic acid (EDTA), and chlorhexidine (CHX), which can cause destructive side effects. Intracanal medicament such as $\mathrm{Ca}(\mathrm{OH})_{2}$ causes collagen breakdown and leads to weakening of radicular dentin. Numerous plants are utilized as phytomedicines in dentistry since they have biological and antibacterial impacts. In endodontics, plants and their extracts can be utilized as irrigant and intracanal medicament to avoid the potential side effects caused by routine chemical agents [9].

Salvadora persica L. (S. persica. Siwak) is a plant whose roots, twigs, or stems have been used for many centuries as oral hygiene tools, particularly in Saudi Arabia. Using Siwak (tooth stick) for cleaning of mouth is advocated Islamic wellestablished beliefs [10].

Many studies have been demonstrated that extracts of $S$. persica possess various antiplaque, antiperiopathic, anticaries, anti-inflammatory, and antimycotic effects [11]. Extracts of $S$. persica as intracanal irrigant also proved significant antimicrobial activity on the oral pathogens in both in vitro and in vivo [12-14]. The present in vitro study was designed to assess the effect of an experimental intracanal medicament based on SPE against the most causative bacteria for endodontic pulpitis/periodontitis; E. faecalis. The gold standard intracanal medicament $\mathrm{Ca}(\mathrm{OH})_{2}$ was employed as positive control. The null hypothesis: there would be no difference between $\mathrm{Ca}(\mathrm{OH})_{2}$, the gold standard endodontic medicament, and SPE as an experimental intracanal medicament in bactericidal activity against E. faecalis for 7 days.

\section{Materials and Methods}

2.1. Materials. The materials used in this study were S. persica sticks brought from Riyadh region in Saudi Arabia, zinc oxide powder (zinc oxide; Prevest DenPro, Bari Brahmana, India), and $\mathrm{Ca}(\mathrm{OH})_{2}$ endodontic medicament (MetaPaste; META BIOMED, Chungcheongbuk-do, Republic of Korea).

The plant was identified by Dr. Talal Dahan, assistant professor of plant classification at Bisha University, Saudi Arabia, and a voucher specimen (\# 19750) was deposited in properly labeled polythene bags for future reference at the Herbarium Centre, College of Pharmacy, Umm Al-Qura
University (UQU), Saudi Arabia. The authors followed IUCN Policy Statement on Research Involving Species at Risk of Extinction.

2.2. Preparation of SPE. The fresh plant sticks of S. persica were freeze-dried and then ground to a fine powder using a commercially available food blender. The ground sample $(500 \mathrm{~g})$ was used to prepare the extract. Consequently, petroleum ether extract was prepared by cold percolating $500 \mathrm{~g}$ of dried powder of the plant sticks in one liter of petroleum ether for $72 \mathrm{~h}$, and every $24 \mathrm{~h}$ fresh solvent was used. The solvent was removed and recovered in a rotary evaporator (BÜCHI Rotavapor RII; Büchi Labortechnik, Flawil, Switzerland) at $40^{\circ} \mathrm{C}$ using a BÜCHI vacuum pump. At the last stage, the oily extract was freeze-dried to ensure that solvents were removed to yield $20 \mathrm{ml}$ of an oily material (SPE) with a powerful aromatic odor. SPE was kept in a brown screwcapped tube in $\mathrm{a}-20^{\circ} \mathrm{C}$ freezer until further analysis.

2.3. Gas Chromatography-Mass Spectrometry GC/MS Analysis. Mass spectra were recorded using Shimadzu GCMS-QP2010 (Kyoto, Japan) equipped with Rtx-5MS fused bonded column $(30 \mathrm{~m} \times 0.25 \mathrm{~mm}$ internal diameter i.d $\times 0.25 \mu \mathrm{m}$ film thickness) (Restek, USA) and a split-splitless injector. The initial column temperature was kept at $50^{\circ} \mathrm{C}$ for $3 \mathrm{~min}$ (isothermal), programmed to $300^{\circ} \mathrm{C}$ at a rate of $5^{\circ} \mathrm{C} /$ min, and kept constant at $300^{\circ} \mathrm{C}$ for $10 \mathrm{~min}$ (isothermal). Injector temperature was $280^{\circ} \mathrm{C}$. Helium carrier gas flow rate was $1.37 \mathrm{ml} / \mathrm{min}$. All the mass spectra were recorded applying the following conditions: (equipment current) filament emission current, $60 \mathrm{~mA}$; ionization voltage, $70 \mathrm{eV}$; and ion source, $220^{\circ} \mathrm{C}$. Diluted samples ( $\left.1 \% \mathrm{v} / \mathrm{v}\right)$ were injected with split mode (split ratio) $1: 15$.

2.3.1. Compounds Identification. The identification of compounds was performed based on their retention indices relative to a homologous series of $n$-alkanes (C8-C28) injected under the same conditions and matching their mass spectra with National Institute of Standards and Technology (NIST) (Gaithersburg, United States) and Wiley Library database (John Wiley \& Sons, Hoboken, New Jersey, United States) as well as literature [15-19].

2.4. Collection of Extracted Teeth. A total sample size of 15 samples for each group was sufficient to reject the null hypothesis that the bactericidal activity for $\mathrm{Ca}(\mathrm{OH})_{2}$ and SPE was equal with probability (power) 0.8 as the true probability of success among the intervention group is 0.65 . The Type I error probability associated with this test of this null hypothesis was 0.05 . The sample size was calculated by $G$ power program 3.1.9.2 (University of Düsseldorf, Düsseldorf, Germany). Forty-five single root premolars extracted teeth for periodontal or orthodontic reasons were obtained from the department of oral surgery at a different governmental and private hospital in Makkah city, Saudi Arabia. Teeth with previous endodontic therapy, fracture, crack, resorption, and root caries were excluded from the 
study. The present study followed the ethical guidelines for clinical investigation: ethical policy of the American Dental Association (ADA) regarding the use of human subjects in clinical research and approved by the Institutional Review Board (IRB), 21 January 2019, Faculty of Dentistry, Umm Al-Qura University, Saudi Arabia (IRB \# 122-19).

\subsection{Preparation of the Experimental Siwak-Based Extract Endodontic Medicament}

2.5.1. Determination of Consistency. The first intended procedure was to determine the appropriate powder/liquid mixing ratio (zinc oxide powder/SPE) for the experimental endodontic medicament. The purpose was to obtain a smooth and homogeneous material whose consistency is acceptable for clinical application. As well, the consistency should be analogous to the control endodontic medicament, commercial $\mathrm{Ca}(\mathrm{OH})_{2}$ paste (MetaPaste). The consistency was accomplished according to ANSI/ADA specification no\# 57 [20]. Using a sterile stainless spatula and glass slab, the powder was added to the SPE in small increments until the cement was of ideal consistency: that is, until it formed a $2.5 \mathrm{~cm}$ string to connect the spatula to the glass plate when the spatula is lifted from the mix (oneinch string method). The paste was creamy in consistency but quite heavy. On obtaining the adequate consistency, the constituents' powder and liquid were quantified. It was found that when one scoop provided with zinc oxide powder mixed with one drop of SPE resulted in the required consistency [21].

2.5.2. Preparation of Extracted Tooth. All forty-five singlerooted premolars were decoronated to standardize their root length. The working length was established to be $14-16 \mathrm{~mm}$, and the roots was undergone rotary standardized instrumentation up to X3-ProTaper Next (DENTSPLY Tulsa Dental Specialties, Dentsply-Maillefer, Switzerland). An irrigant 2.5\% sodium hypochlorite $\mathrm{NaOCl}$ (HYPOSOL; Prevest DenPro, Bari Brahmana, India) was used in each instrument and finally dried with size 25 absorbent paper points. Each root was placed in a closed test tube containing $3 \mathrm{ml}$ of brain heart infusion (BHI) broth (BHI BROTH; SPML-Saudi Prepared Media Laboratory, Riyadh, Saudi Arabia) and sterilized by autoclaving at $121^{\circ} \mathrm{C}$ for $20 \mathrm{~min}$ and then incubated for $24 \mathrm{~h}$ at $37^{\circ} \mathrm{C}$ to confirm sterility by the absence of turbidity.

2.5.3. Preparation of E. faecalis Suspension. E faecalis ATCC 29212 strain was grown on Bile Esculin agar media (BILE AESCULIN AGAR; SPML-Saudi Prepared Media Laboratory, Riyadh, Saudi Arabia) at $37^{\circ} \mathrm{C}$ for $24 \mathrm{~h}$. After growth, bacterial suspension was prepared from grown bacterial colonies by inoculation in brain heart infusion (BHI) broth and adjusted to the optical density of approximately $1.5 \times 10^{8} \mathrm{CFU} / \mathrm{ml}$ by comparing its turbidity to a 0.5 McFarland standard spectrophotometrically.
2.5.4. Infection of Root Canals. Two $\mathrm{ml}$ of sterile BHI broth was removed from each root containing tube and replaced by $2 \mathrm{ml}$ of the prepared bacterial suspension. The tubes were then closed and incubated at $37^{\circ} \mathrm{C}$ for $48 \mathrm{~h}$.

2.5.5. Colony-Forming Unit-1 (CFU-1). After $48 \mathrm{~h}$, predetermined contamination period of root canals was elapsed, each root was removed from the tube under complete aseptic precautions, and irrigated with sterile saline $(100 \mu \mathrm{l})$. Later, a dry sterile absorbent paper of point size 25 was inserted into the root canal and left for $5 \mathrm{~min}$. Afterwards, these paper points were transferred individually to sterile test tubes, each containing $1 \mathrm{ml}$ of sterile saline solution, vortexed for 30 seconds, and then four serial dilutions were made for each tube. Aliquots of $10 \mu \mathrm{l}$ of each dilution were plated onto Bile Esculin (BE) agar plates and incubated at $37^{\circ} \mathrm{C}$ for $24 \mathrm{~h}$. The grown bacterial colonies were counted and multiplied by their dilution factor to represent CFU-1/ $\mathrm{ml}$.

2.5.6. Ex Vivo Testing of Antimicrobial Activity of the Experimental Medicaments. The 45 decoronated teeth were randomly allocated into 3 equal groups $(n=15)$ by simple random sampling using random digit table depending on medicament used:

Group I: experimental Siwak extract-based
medicament Group II: $\mathrm{Ca}(\mathrm{OH})_{2}$ paste (positive control)

Group III: sterile physiological saline as negative control group

Medicaments were placed into root canals with lentulo spiral (Dentsply-Maillefer, Swaziland) inserted to the full working length. The root canal foramina were sealed by sterile cotton pellets and the orifices closed by temporary restoration; then, the samples were kept in an incubator at $37^{\circ} \mathrm{C}$ for seven days.

2.5.7. Colony-Forming Unit-2 (CFU-2). Seven days later, each root was irrigated with sterile normal saline, and then the previous technique was repeated to obtain CFU-2.

2.5.8. The Minimal Inhibitory Concentration (MIC) and Minimal Bactericidal Concentration (MBC) of SPE. The MIC of the SPE was determined in 96 multiwell microtiter plates using microdilution method [22] with minor modifications. SPE was adjusted to a concentration of $50 \mathrm{mg} / \mathrm{ml}$ in cation-adjusted Mueller Hinton broth medium, then pipetted $50 \mu \mathrm{l}$ of cation-adjusted Mueller Hinton broth medium into the first well of the plate, and $50 \mu \mathrm{l}$ of broth medium was distributed from the 1st to the 12th well of each row. Twofold serial dilution was achieved by transferring $50 \mu \mathrm{l}$ of scalar dilution from the first to the subsequent wells of each row. The final concentration of SPE adopted to evaluate antibacterial activity was included from $25 \mathrm{mg} / \mathrm{ml}$ to $0.003 \mathrm{mg} / \mathrm{ml}$. Finally, $10 \mu \mathrm{L}$ of E. faecalis suspension was 
added to each well. Two row lines in each plate were used as controls: one row line with $\mathrm{Ca}(\mathrm{OH})_{2}$ as a positive control (in a serial dilution of $25-0.003 \mathrm{mg} / \mathrm{mL}$ ). Plates were incubated at $37^{\circ} \mathrm{C}$ for $18-24 \mathrm{~h}$. The lowest concentration at which no turbidity occurred was taken as the MIC value. Plates were analyzed individually to determine MIC, and the average MIC values from three repeats were taken in determination of the final MIC values for each extract to ensure accuracy and reproducibility. To determine the MBC of SPE, $50 \mu \mathrm{l}$ of the solution was removed from the well before the MIC well and the well after the MIC well. The solution was inoculated into tryptic soy agar plate and incubated at $37^{\circ} \mathrm{C}$ for $24 \mathrm{~h}$.

2.6. Statistical Analysis. Data were collected, tabulated, and statistically analyzed using Statistical Package for Social Science (SPSS v.20, IBM. Released 2020. IBM SPSS Statistics for Windows, Version 27.0. Armonk, NY: IBM). $P<0.05$ was considered as a level of significance. The mean and standard deviation were tabulated and statistically analyzed using one-way ANOVA test regarding the CFU-1 of the three tested groups before using intracanal medication. Regarding the CFU-2 of three groups, the mean and standard deviation were analyzed using one-way nonparametric ANOVA (Kruskal-Wallis). Finally, the antimicrobial effect of different tested medications on E. faecalis was tabulated and statistically analyzed using paired $t$-test.

\section{Results}

3.1. Chemical Composition of SPE. Analysis of SPE by GC and GC/MS revealed that SPE contained 32 compounds, of which benzyl isothiocyanate $(33.32 \%), \gamma$-sitosterol $(25.76 \%)$, stigmasterol (5.92\%), $\beta$-sitosterol acetate (2.28\%), $n$-hexadecanoic acid (4.27\%), and (Z)-11-octadecenoic acid $(3.16 \%)$ were found to be the major constituents. Compounds are listed in order of their elution times on Rtx-5MS column in Table 1.

3.2. SPE Endodontic Therapy. The statistical analysis of the CFU-1 of three tested groups before using intracanal medications ( $\mathrm{SPE}$ and $\mathrm{Ca}(\mathrm{OH})_{2}$ ) was tabulated in Table 2 . It was evident that there were no significant differences in bacterial counts among them $(P=0.359)$. Table 2 shows the statistical analysis using paired $t$-test of the number of the CFU of E. faecalis before and after applying the investigated medicaments at the root canal lumens; CFU-1 and CFU-2, respectively. The results showed a significant difference between CFU-1 and CFU-2 either in using SPE $(P=0.006)$ or $\mathrm{Ca}(\mathrm{OH})_{2}(P=0.011)$. On the other hand, the bacterial count of the negative control group showed a nonsignificant difference between CFU-1 and CFU-2 $(P=0.438)$. Finally, the bacterial count's significant difference among the three tested groups was compared using one-way nonparametric ANOVA. The values were insignificantly different between bacterial counts after using SPE and $\mathrm{Ca}(\mathrm{OH})_{2}(P=0.210)$. On the contrary, comparing both medicaments with the negative control saline group resulted in significant differences $(P=0.001)$ and $(P=0.007)$, respectively.
3.3. MIC and MBC of SPE. The MIC of SPE and $\mathrm{Ca}(\mathrm{OH})_{2}$ were measured to be 3.5 and $4.2 \mathrm{mg} / \mathrm{ml}$, respectively. No growth in the MIC well and the well before that and bacterial growth in the well after the MIC well indicated equality of $\mathrm{MBC}$ and MIC of SPE.

\section{Discussion}

The chemomechanical cleaning and shaping of the root canals of the teeth are essential for the success of endodontic therapy $[23,24]$. Yet, intracanal medication is a crucial procedure during root canal treatment where the probability of complete eradication of bacteria is questionable [25].

It is well documented that the use of biocompatible intracanal medications possessing antimicrobial properties between appointments destroys and eradicates bacteria in the root canal system [26]. It was proven that E. faecalis is the most predominant bacteria found in the infected root canal [27]. Unfortunately, this species has the ability to survive in hard environment with deprived nutrients and alkaline $\mathrm{pH}$ reaching up to 11.5 that implies a challenge to be completely exterminated from root canal system $[28,29]$.

Calcium hydroxide $\mathrm{Ca}(\mathrm{OH})_{2}$ is the gold standard intracanal medication used in the treatment of infected root canals, referring to its well-known antibacterial features and ease of application [30, 31]. The effect of both SPE and $\mathrm{Ca}(\mathrm{OH})_{2}$ against $E$. faecalis was considered in the presence of a negative control group saline, to specify the antimicrobial effect. The antimicrobial effect of the experimental medicament SPE insignificantly surpasses that of $\mathrm{Ca}(\mathrm{OH})_{2}$ $(P=0.210)$, as shown in Table 2 . In the present investigation, SPE experimental intracanal medicament (Group 1) proved an effective eradication of $E$. faecalis. This finding was in agreement with the results reported about the usefulness of SPE as endodontic irrigant against E. faecalis [32]. As well, it was evidenced that $S$. persica has an inhibitory effect on the growth of the oral pathogen [33]. The MIC value of SPE was in agreement with those reported for aqueous and methanol extracts of $S$. persica against E. faecalis [34] and for $\mathrm{Ca}(\mathrm{OH})_{2}$ [35]. MIC of SPE is recorded in the current study for the first time.

In this study, the chemical profile representing 32 compounds of SPE was identified by GC/MS (89.09\%) and listed in Table 1. The major component was found to be benzyl isothiocyanate. This compound was reported as the most robust antibacterial component with high bactericidal activity against Gram-negative periodontal pathogens [36]. The potent antibacterial effect of the experimental medicament, as shown in Table 2, suggested that SPE targeted the bacterial membrane, whereas BITC has both lipophilic and electrophilic properties. It is reported that BITC penetrates through the outer bacterial membrane and possibly interfered with the bacterial redox systems, thus hampering the bacterium's ability to maintain its membrane potential. Such an effect of BITC has been demonstrated for mitochondrial membranes [37].

In addition, there are $\gamma$-sitosterol (25.76\%), $n$-hexadecanoic acid (4.27\%), and (Z)-11-octadecenoic acid $(3.16 \%)$ that are reported as potent broad-spectrum 
TABLE 1: The chemical profile of SPE.

\begin{tabular}{|c|c|c|c|c|c|c|c|}
\hline Peak \# & $R_{t}$ & Component & $\begin{array}{l}\text { Molecular } \\
\text { formula }\end{array}$ & $R I_{\text {exp }}{ }^{a}$ & $R I_{\text {lit }}^{b}$ & Content (\%) & Identification $^{c}$ \\
\hline 1. & 18.35 & Carvacrol & $\mathrm{C}_{10} \mathrm{H}_{14} \mathrm{O}$ & 1288 & 1288 & 0.57 & MS, KI \\
\hline 2. & 20.47 & Benzyl isothiocyanate & $\mathrm{C}_{8} \mathrm{H}_{7} \mathrm{NS}$ & 1361 & 1359 & 33.32 & MS, KI \\
\hline 3. & 21.14 & $n$-Tetradecane & $\mathrm{C}_{14} \mathrm{H}_{30}$ & 1384 & 1400 & 0.21 & MS, KI \\
\hline 4. & 23.76 & $n$-Pentadecane & $\mathrm{C}_{15} \mathrm{H}_{32}$ & 1485 & 1500 & 0.38 & MS, KI \\
\hline 5. & 26.24 & $n$-Hexadecane & $\mathrm{C}_{16} \mathrm{H}_{34}$ & 1582 & 1600 & 0.13 & MS, KI \\
\hline 6. & 34.40 & $n$-Hexadecanoic acid (palmitic acid) & $\mathrm{C}_{16} \mathrm{H}_{32} \mathrm{O}_{2}$ & 1948 & 1946 & 4.27 & MS, KI \\
\hline 7. & 34.91 & Hexadecanoic acid ethyl ester & $\mathrm{C}_{18} \mathrm{H}_{36} \mathrm{O}_{2}$ & 1972 & 1975 & 0.13 & MS, KI \\
\hline 8. & 36.12 & Cyclic octaatomic sulphur & $\mathrm{S}_{8}$ & 2034 & 2055 & 0.99 & MS, KI \\
\hline 9. & 37.86 & Oleic acid & $\mathrm{C}_{18} \mathrm{H}_{34} \mathrm{O}_{2}$ & 2130 & 2130 & 1.95 & MS, KI \\
\hline 10. & 37.92 & (Z)-11-Octadecenoic acid & $\mathrm{C}_{18} \mathrm{H}_{34} \mathrm{O}_{2}$ & 2133 & 2117 & 3.16 & MS, KI \\
\hline 11. & 38.15 & $\begin{array}{c}(Z, Z)-9,12 \text {-Octadecadienoyl chloride (linoleic acid } \\
\text { chloride) }\end{array}$ & $\mathrm{C}_{18} \mathrm{H}_{31} \mathrm{ClO}$ & 2146 & 2139 & 0.37 & MS, KI \\
\hline 12. & 38.24 & (Z)-9-Octadecenoic acid ethyl ester (oleic acid ethyl ester) & $\mathrm{C}_{20} \mathrm{H}_{38} \mathrm{O}_{2}$ & 2151 & 2168 & 0.45 & MS, KI \\
\hline 13. & 38.36 & 9-Octadecenoic acid ethyl ester & $\mathrm{C}_{20} \mathrm{H}_{38} \mathrm{O}_{2}$ & 2157 & 2171 & 0.14 & MS, KI \\
\hline 14. & 42.84 & $p$-Cresol, $2,2^{\prime}$-methylene bis [6-tert-butyl- & $\mathrm{C}_{23} \mathrm{H}_{32} \mathrm{O}_{2}$ & 2403 & 2398 & 0.13 & MS, KI \\
\hline 15. & 48.95 & Squalene & $\mathrm{C}_{30} \mathrm{H}_{50}$ & 2796 & 2814 & 0.17 & MS, KI \\
\hline 16. & 49.51 & N-Benzylpalmitamide & $\mathrm{C}_{23} \mathrm{H}_{39} \mathrm{NO}$ & 2832 & 2880 & 0.36 & MS \\
\hline 17. & 51.09 & Stigmasta-3,5-diene & $\mathrm{C}_{29} \mathrm{H}_{48}$ & 2934 & - & 0.77 & MS \\
\hline 18. & 51.69 & Stigmasterol acetate & $\mathrm{C}_{31} \mathrm{H}_{50} \mathrm{O}_{2}$ & 2972 & 2879 & 0.12 & MS, KI \\
\hline 19. & 51.87 & $3 \beta$-Acetoxystigmasta- $4,6,22$-triene & $\mathrm{C}_{31} \mathrm{H}_{48} \mathrm{O}_{2}$ & 2984 & - & 0.24 & MS \\
\hline 20. & 52.06 & $n$-Benzyloctadecenamide ( $n$-benzyloleamide) & $\mathrm{C}_{25} \mathrm{H}_{41} \mathrm{NO}$ & 2996 & 2991 & 0.53 & MS, KI \\
\hline 21. & 52.17 & Stigmasta-5,22-dien-3-ol, acetate & $\mathrm{C}_{31} \mathrm{H}_{50} \mathrm{O}_{2}$ & 3003 & - & 0.65 & MS \\
\hline 22. & 52.47 & Clionasterol acetate & $\mathrm{C}_{31} \mathrm{H}_{52} \mathrm{O}_{2}$ & 3022 & - & 0.50 & MS \\
\hline 23. & 52.66 & Stigmastan-3,5,22-triene & $\mathrm{C}_{29} \mathrm{H}_{46}$ & 3034 & 2981 & 1.89 & MS, KI \\
\hline 24. & 52.94 & $\beta$-Sitosterol acetate & $\mathrm{C}_{31} \mathrm{H}_{52} \mathrm{O}_{2}$ & 3052 & - & 2.28 & MS \\
\hline 25. & 53.28 & Cholesterol & $\mathrm{C}_{27} \mathrm{H}_{46} \mathrm{O}$ & 3074 & 3075 & 0.66 & MS, KI \\
\hline 26. & 54.89 & Campesterol & $\mathrm{C}_{28} \mathrm{H}_{48} \mathrm{O}$ & 3177 & 3131 & 0.70 & MS \\
\hline 27. & 55.40 & Stigmasterol & $\mathrm{C}_{29} \mathrm{H}_{48} \mathrm{O}$ & 3210 & 3213 & 5.92 & MS, KI \\
\hline 28. & 56.44 & $\gamma$-Sitosterol & $\mathrm{C}_{29} \mathrm{H}_{50} \mathrm{O}$ & 3277 & 3290 & 25.76 & MS, KI \\
\hline 29. & 57.47 & Unidentified & - & 3344 & - & 3.57 & - \\
\hline 30. & 58.21 & 3,5-Stigmastadien-7-one & $\mathrm{C}_{29} \mathrm{H}_{46} \mathrm{O}$ & 3391 & - & 0.56 & MS \\
\hline 31. & 59.04 & Sitostenone & $\mathrm{C}_{29} \mathrm{H}_{48} \mathrm{O}$ & 3444 & 3435 & 0.54 & MS, KI \\
\hline 32. & 60.19 & $\begin{array}{l}\text { Lupeol } \\
\% \text { total identified }\end{array}$ & $\mathrm{C}_{30} \mathrm{H}_{50} \mathrm{O}$ & 3518 & 3451 & $\begin{array}{l}1.24 \\
89.09\end{array}$ & MS \\
\hline
\end{tabular}

Compounds are listed in order of their elution times on Rtx-5MS column. ${ }^{\mathrm{a}} \mathrm{R} I_{\text {exp }}$, retention index determined experimentally relative to C8 - C28 $n$-alkanes on Rtx-5MS column; ${ }^{\mathrm{b}} R I_{l i}$, published retention indices; ' ${ }^{\mathrm{C}}$ Identification, was based on comparison of the compounds' mass spectral data (MS) and retention indices (RI) with those of NIST Mass Spectral Library (2017), Wiley Registry of Mass Spectral Data $8^{\text {th }}$ edition and literature. Bold shows major components.

TABLE 2: The descriptive statistical analysis of the E. faecalis count before (CFU-1) and after (CFU-2) the application of the medicaments.

\begin{tabular}{lcc}
\hline Bacterial count groups & CFU-1 & CFU-2 \\
& Mean \pm SD & $0.0250 \pm 0.1 * 10^{4}$ \\
Group I Siwak & $48.9 \pm 53.7 * 10^{4}$ & $0.07 \pm 0.25 * 10^{4}$ \\
Group II Ca(OH) $)_{2}$ (+ve control) & $51.6 \pm 68.4 * 10^{4}$ & $50 \pm 115 * 10^{4}$ \\
Group III Saline (-ve control) & $56.3 \pm 59 * 10^{4}$ & $50 \pm 115$ \\
\hline
\end{tabular}

antimicrobials [38-42]. Moreover, SPE has antimicrobial effect against both Gram-positive and Gram-negative bacteria due to the presence of carvacrol $(0.57 \%)$ confirmed by Memar et al. (2017) [43]. SPE components in Table 1 show the presence of $n$-tetradecane $(0.21 \%), n$-hexadecane $(0.13 \%)$, 11-octadecenoic acid $(3.16 \%)$, squalene $(0.17 \%)$, stigmasterol $(0.12 \%)$, sitosterol $(2.28 \%)$, and sitostenone $(0.54 \%)$, and these components are potent antibacterial agents [44-48]. Therefore, SPE's strong bactericidal effect is attributed to the antimicrobial components that represents a percentage of $70.71 \%$ of the extract. It is worthy to mention that some components with anti-inflammatory and antioxidant effects are identified as oleic acid (1.95\%), 11octadecenoic acid (3.16\%), 2,2'-methylenebis (6-tert-butyl4-methylphenol) $(0.13 \%)$, squalene $(0.17 \%), n$-benzyloleamide $(0.53 \%), n$-benzylpalmitamide $(0.36 \%)$ stigmasta-5, 22-dien-3-ol (0.65\%) lupeol (1.24\%), and hexadecanoic acid, ethyl ester $(0.13 \%)$ [ $46,47,49]$.

Based on the obtained results, the null hypothesis is accepted as the experimental intracanal medicament SPE, a novel trial in the field of endodontic treatment, has nonsignificant difference in antimicrobial activity comparing to the gold standard; $\mathrm{Ca}(\mathrm{OH})_{2}$ against E. faecalis. However, further studies are suggested to explicate SPE effect against 
other reported endodontic pathogens. Moreover, the limitations of this study as the assessment of the activity against the biofilm formation that resembles the clinical situation should be investigated after the evaluation of the effect of SPE in an in vivo study. SPE comprises potent antimicrobial and anti-inflammatory components as identified by GC/MS. Thus, it could be claimed that it will be a robust intracanal medicament. However, its anti-inflammatory effect is still under investigation by the authors.

\section{Conclusion}

Within the limitations of this Ex vivo study, SPE can efficiently eradicate $E$. faecalis from the root canal system by many antimicrobial components. It could be used as a good alternative to calcium hydroxide in endodontic therapy; however, further studies are recommended to investigate its efficacy in an in vivo assessment and inhibitory effects on biofilm formation before engaging it in regular dental practice.

\section{Data Availability}

The data that support the findings of this study are openly available from the corresponding author on reasonable request.

\section{Conflicts of Interest}

The authors declare no conflicts of interest.

\section{Authors' Contributions}

N. A., N. B., and S. A. conceptualized the study; A. A., R. A., R. Q., N. S., and I. A. were responsible for methodology; A. N. was responsible for software; N. S., N. A., and N. B. validated the data; N. S. performed formal analysis and visualized the study; N. A. investigated the data and contributed resources and was involved in project administration and funding acquisition; A. A. and R. A. contributed to data curation; A. A., R. A., N. S., and I. A. prepared the original draft; N. A., N. S., and N. B. reviewed and edited the manuscript; N. B. performed study supervision. All authors have read and agreed to the published version of the manuscript.

\section{Acknowledgments}

The authors would like to thank the Deanship of Scientific Research DSR at Umm Al-Qura University for supporting this work by Grant Code: 19-MED-1-03-0010.

\section{Supplementary Materials}

S1: Salvadora persica plants' sticks. S2: Salvadora persica petether extract. S3: prepared 45 extracted teeth. S4: prepared 45 extracted teeth in BHI tubes and prepared for incubation at $37^{\circ} \mathrm{C}$ for 48 hours. Two $\mathrm{ml}$ of sterile $\mathrm{BHI}$ broth was removed from each root-containing tube and replaced by $2 \mathrm{ml}$ of the prepared bacterial suspension. The tubes were then closed and incubated at $37^{\circ} \mathrm{C}$ for $48 \mathrm{~h}$. S5: bile esculin (BE) agar showing a high number of growing colonies of $E$. faecalis before application of medicaments. S6: BE agar showing no growing colonies of $E$. faecalis after application of Siwak as a medicament (CFU2). S7: BE agar showing a few number of growing colonies of $E$. faecalis after application of $\mathrm{Ca}(\mathrm{OH})_{2}$ (CFU2). S8: BE agar showing a high number of growing colonies of E. faecalis after using saline (CFU2). S9: GC/MS total ion chromatogram (TIC) of Salvadora sp. petroleum ether extract. GCMS revealed the identification of 32 compounds from SPE by comparing their mass spectra with the National Institute of Standards and Technology (NIST) (Gaithersburg, United States) and Wiley library database (John Wiley \& Sons, Hoboken, New Jersey, United States), as well as the literature. (Supplementary Materials)

\section{References}

[1] J. F. Siqueira Jr, K. M. Magalhães, and I. N. Rôças, "Bacterial reduction in infected root canals treated with $2.5 \% \mathrm{NaOCl}$ as an irrigant and calcium hydroxide/camphorated paramonochlorophenol paste as an intracanal dressing," Journal of Endodontics, vol. 33, no. 6, pp. 667-672, 2007.

[2] K. S. Tan, V. S. H. Yu, S. Y. Quah, and G. Bergenholtz, "Rapid method for the detection of root canal bacteria in endodontic therapy," Journal of Endodontics, vol. 41, no. 4, pp. 447-450, 2015.

[3] I. N. Rôças, J. F. Siqueira Jr, and K. R. Santos, "Association of Enterococcus faecalis with different forms of periradicular diseases," Journal of Endodontics, vol. 30, no. 5, pp. 315-320, 2004.

[4] J. Shabbir, F. Qazi, W. Farooqui, S. Ahmed, T. Zehra, and Z. Khurshid, "Effect of Chinese propolis as an intracanal medicament on post-operative endodontic pain: a doubleblind randomized controlled trial," International Journal of Environmental Research and Public Health, vol. 17, no. 2, 2020.

[5] J. Shabbir, Z. Khurshid, F. Qazi et al., "Effect of different hostrelated factors on postoperative endodontic pain in necrotic teeth dressed with interappointment intracanal medicaments: a multicomparison study," European Journal of Dermatology, vol. 15, no. 1, pp. 152-157, 2021.

[6] C. A. Rivera-Albarran, V. Morales-Dorantes, J. L. AyalaHerrera et al., "Antibiotic resistance decreases the efficacy of endodontic filling pastes for root canal treatment in children's teeth," Children, vol. 8, no. 8, 2021.

[7] I. F. d. A. S. Ramos, M. T. Biz, N. Paulino et al., "Histopathological analysis of corticosteroid-antibiotic preparation and propolis paste formulation as intracanal medication after pulpectomy: an in vivo study," Journal of Applied Oral Science, vol. 20, no. 1, pp. 50-56, 2012.

[8] I. Portenier, T. Waltimo, D. Orstavik, and M. Haapasalo, "The susceptibility of starved, stationary phase, and growing cells of Enterococcus faecalis to endodontic medicaments," Journal of Endodontics, vol. 31, no. 5, pp. 380-386, 2005.

[9] V. Andamuthu Sivakumar, V. Ravi, A. S. Prasad, and J. S. Sivakumar, "Herbendodontics - phytotherapy in endodontics: a review," Biomedical and Pharmacology Journal, vol. 11, no. 2, pp. 1073-1082, 2018.

[10] M. Farag, W. M. Abdel-Mageed, A. A. El Gamal, and O. A. Basudan, "Salvadora persica L.: toothbrush tree with health benefits and industrial applications-an updated evidence-based review," Saudi Pharmaceutical Journal, vol. 29, no. 7, 2021. 
[11] M. M. Haque and S. A. Alsareii, "A review of the therapeutic effects of using miswak (Salvadora Persica) on oral health," Saudi Medical Journal, vol. 36, no. 5, pp. 530-543, 2015.

[12] A. El-Latif Hesham and S. A. Alrumman, "Antibacterial activity of miswak Salvadora persica extracts against isolated and genetically identified oral cavity pathogens," Technology and Health Care, vol. 24, no. s2, pp. S841-S848, 2016.

[13] B. N. Wali, I. K. Afif, J. F. Balata, and N. A. Badr, "Effect of an exprimental mouth wash extracted from Salvadora persica on cariogenic bacteria and dental plaque formation," Int. J. Curr. Res.vol. 10, no. 10, pp. 64070-64075, 2018.

[14] T. H. Al-Salman, M. G. A. S. Ali, and O. M. Al-Nu'aimy, "The antimicrobial effect of water extraction of Salvadora persica (Miswak) as a root canal irrigant," RDENTJ, vol. 5, no. 1, pp. 33-36, 2005.

[15] R. P. Adams, Identification of Essential Oil Components by Gas Chromatography/mass Spectrometry, Allured publishing corporation Carol Stream, IL, USA, 2007.

[16] I. M. Ayoub, F. S. Youssef, M. El-Shazly, M. L. Ashour, A. N. Singab, and M. Wink, "Volatile constituents of Dietes bicolor (Iridaceae) and their antimicrobial activity," Zeitschrift fur Naturforschung. C, Journal of biosciences, vol. 70, no. 7-8, pp. 217-225, 2015.

[17] W. M. Elkady and I. M. Ayoub, "Chemical profiling and antiproliferative effect of essential oils of two Araucaria species cultivated in Egypt," Industrial Crops and Products, vol. 118, pp. 188-195, 2018.

[18] H. A. Gad, I. M. Ayoub, and M. Wink, "Phytochemical profiling and seasonal variation of essential oils of three Callistemon species cultivated in Egypt," PloS one, vol. 14, no. 7, Article ID e0219571, 2019.

[19] R. M. Labib, I. M. Ayoub, H. E. Michel et al., "Appraisal on the wound healing potential of Melaleuca alternifolia and Rosmarinus officinalis L. essential oil-loaded chitosan topical preparations," PloS one, vol. 14, no. 9, Article ID e0219561, 2019.

[20] "Instruments; Equipment, ANSI/ADA specification no. 57 for endodontic filling materials," The Journal of the American Dental Association, vol. 108, 1984.

[21] J. Ingle, L. Bakland, and Endodontics, Restoration of Endodontically Treated Teeth, BC Decker Inc Hamilton-London, London, UK, 5th edition, 2002.

[22] S. D. Sarker, L. Nahar, and Y. Kumarasamy, "Microtitre platebased antibacterial assay incorporating resazurin as an indicator of cell growth, and its application in the in vitro antibacterial screening of phytochemicals," Methods, vol. 42, no. 4, pp. 321-324, 2007.

[23] P. N. R. Nair, U. Sjögren, G. Krey, K.-E. Kahnberg, and G. Sundqvist, "Intraradicular bacteria and fungi in root-filled, asymptomatic human teeth with therapy-resistant periapical lesions: a long-term light and electron microscopic follow-up study," Journal of Endodontics, vol. 16, no. 12, pp. 580-588, 1990.

[24] C. M. Mônika and I. C. Fröner, "A scanning electron microscopic evaluation of different root canal irrigation regimens," Brazilian Oral Research, vol. 20, no. 3, pp. 235-240, 2006.

[25] B. S. Chong and T. R. P. Ford, "The role of intracanal medication in root canal treatment," International Endodontic Journal, vol. 25, no. 2, pp. 97-106, 1992.

[26] C. Sathorn, P. Parashos, and H. Messer, "Australian endodontists' perceptions of single and multiple visit root canal treatment," International Endodontic Journal, vol. 42, no. 9, pp. 811-818, 2009.
[27] M. Pourhajibagher, R. Ghorbanzadeh, and A. Bahador, "Culture-dependent approaches to explore the prevalence of root canal pathogens from endodontic infections," Brazilian Oral Research, vol. 31, p. e108, 2017.

[28] F. Alghamdi and M. Shakir, "The Influence of Enterococcus faecalis as a dental root canal pathogen on endodontic treatment: a systematic review," Cureus, vol. 12, no. 3, Article ID e7257, 2020.

[29] I. Prada, P. Mico-Munoz, T. Giner-Lluesma, P. Mico-Martinez, N. Collado-Castellano, and A. Manzano-Saiz, "Influence of microbiology on endodontic failure. Literature review," Medicina Oral, Patología Oral y Cirugía Bucal, vol. 24, no. 3, pp. e364-e372, 2019.

[30] M. Asnaashari, M. J. Eghbal, A. S. Yaghmayi, M. Shokri, and S. Azari-Marhabi, "Comparison of antibacterial effects of photodynamic therapy, modified triple antibiotic paste and calcium hydroxide on root canals infected with Enterococcus Faecalis: an in-vitro study," Journal of Lasers in Medical Sciences, vol. 10, no. 4, pp. 23-29, 2019.

[31] B. Athanassiadis, P. Abbott, N. George, and L. Walsh, "Anin vitrostudy of the antimicrobial activity of some endodontic medicaments and their bases using an agar well diffusion assay," Australian Dental Journal, vol. 54, no. 2, pp. 141-146, 2009.

[32] F. M. Al Qarni, F. M. ElFasakhany, L. M. Kenawi, and A. M. Moustafa, "Antimicrobial activity of Azadirachta indica (neem) and Salvadora persica (miswak) extracts as endodontic irrigants," Endodontics \& Dental Traumatology, vol. 13, no. 3, 2019.

[33] A. El-Latif Hesham and S. A. Alrumman, "Antibacterial activity of Miswak Salvadora persica extracts against isolated and genetically identified oral cavity pathogens," Technology and Health Care, vol. 24, no. s2, pp. S841-S848, 2016.

[34] M. S. Al-Ayed, A. M. Asaad, M. A. Qureshi, H. G. Attia, and A. H. AlMarrani, "Antibacterial activity of Salvadora persica L. (Miswak) extracts against multidrug resistant bacterial clinical isolates," Evid Based Complement Alternat Med, vol. 2016, Article ID 7083964, 16 pages, 2016.

[35] Y. L. Su and X. Y. Wang, "Inhibition of Enterococcus faecalis by calcium peroxide," Chinese Journal of Dental Research: The Official Journal of the Scientific Section of the Chinese Stomatological Association (CSA), vol. 19, no. 2, pp. 109-113, 2016.

[36] A. Sofrata, E. M. Santangelo, M. Azeem, A. K. Borg-Karlson, A. Gustafsson, and K. Pütsep, "Benzyl isothiocyanate, a major component from the roots of Salvadora persica is highly active against Gram-negative bacteria," PLoS One, vol. 6, no. 8, Article ID e23045, 2011.

[37] Y. Nakamura, M. Kawakami, A. Yoshihiro et al., "Involvement of the mitochondrial death pathway in chemopreventive benzyl isothiocyanate-induced apoptosis," Journal of Biological Chemistry, vol. 277, no. 10, pp. 8492-8499, 2002.

[38] J. Patra, G. Das, and K.-H. Baek, "Chemical composition and antioxidant and antibacterial activities of an essential oil extracted from an edible seaweed, Laminaria japonica L," Molecules, vol. 20, no. 7, pp. 12093-12113, 2015.

[39] W. A. S. Tunjung, D. Liana, and L. Hidayati, "Antibacterial activity and composition of crude extracts of kaffir lime (Citrus hystrix DC.) leaves and callus," Proceedings of the Pakistan Academy of Sciences B, vol. 55, no. 2, pp. 45-53, 2018.

[40] C. Nweze, H. Ibrahim, and G. I. Ndukwe, "Beta-sitosterol with antimicrobial property from the stem bark of pomegranate (Punica granatum Linn)," Journal of Applied Sciences \& Environmental Management, vol. 23, no. 6, pp. 1045-1049, 2019. 
[41] Z.-H. Pu, Y.-Q. Zhang, Z.-Q. Yin et al., "Antibacterial activity of 9-octadecanoic acid-hexadecanoic acid-tetrahydrofuran3,4-diyl ester from neem oil," Agricultural Sciences in China, vol. 9, no. 8, pp. 1236-1240, 2010.

[42] K. Y. Chen, I. H. Kim, C. T. Hou, Y. Watanabe, and H.-R. Kim, "Monoacylglycerol of 7,10-dihydroxy-8(E)-octadecenoic acid enhances antibacterial activities against foodborne bacteria," Journal of Agricultural and Food Chemistry, vol. 67, no. 29, pp. 8191-8196, 2019.

[43] M. Y. Memar, P. Raei, N. Alizadeh, M. Akbari Aghdam, and H. S. Kafil, "Carvacrol and thymol: strong antimicrobial agents against resistant isolates," Reviews in Medical Microbiology, vol. 28, no. 2, pp. 63-68, 2017.

[44] L. Ravi, K. Krishnan, A. Olatunji et al., "In vitro cytotoxicity of norviburtinal and isopinnatal from Kigelia pinnata against cancer cell lines," Asian Journal of Cell Biology, vol. 12, no. 1, pp. 158-164, 2009.

[45] L. S. Rouis-Soussi, A. El Ayeb-Zakhama, A. Mahjoub, G. Flamini, H. B. Jannet, and F. Harzallah-Skhiri, "Chemical composition and antibacterial activity of essential oils from the Tunisian Allium nigrum L," EXCLI journal, vol. 13, p. 526, 2014.

[46] K. Mazumder, A. Nabila, A. Aktar, and A. Farahnaky, "Bioactive variability and in vitro and in vivo antioxidant activity of unprocessed and processed flour of nine cultivars of Australian lupin species: a comprehensive substantiation," Antioxidants, vol. 9, no. 4, p. 282, 2020.

[47] M. M. Rahman, S. H. Ahmad, M. T. Mohamed, and M. Z. Ab Rahman, "Antimicrobial compounds from leaf extracts of Jatropha curcas, Psidium guajava, and Andrographis paniculata," TheScientificWorldJOURNAL, vol. 2014, Article ID 635240, 16 pages, 2014.

[48] M. A. Lozano-Grande, S. Gorinstein, E. Espitia-Rangel, G. Dávila-Ortiz, and A. L. Martínez-Ayala, "Plant sources, extraction methods, and uses of squalene," Int. J. Agron, vol. 2018, Article ID 1829160, 9 pages, 2018.

[49] N. Erdinest, O. Shmueli, Y. Grossman, H. Ovadia, and A. Solomon, "Anti-inflammatory effects of alpha linolenic acid on human corneal epithelial cells," Investigative Opthalmology \& Visual Science, vol. 53, no. 8, pp. 4396-4406, 2012. 